\title{
An innovative laboratory characterization: hydrogen interaction with X60 pipeline steel
}

\author{
Renzo Valentini ${ }^{1}$, Giovanna Gabetta $^{2}$, Linda Bacchi $^{3}$, Serena Corsinovi ${ }^{3}$, Michele Villa ${ }^{3 *}$ \\ ${ }^{1}$ Pisa University, DICI, Pisa 56122, Italy \\ ${ }^{2}$ Expert in SSC and HE, Consultant \\ ${ }^{3}$ Letomec Srl, Pisa 56023, Italy
}

\begin{abstract}
Corrosion is evaluated to be one of the most important cause for pipeline failures. Given the serious consequences of these events in terms of human safety, environmental preservation and cost saving, it is evident that on-field corrosion control could have a fundamental role. The aim of the present work was to meet this need with preliminary feasibility study to develop a test procedure, characterized at the same time by non-invasive approach and scientific rigor, to evaluate the possibility of on-line monitoring and assess the integrity of a pipeline during its operation. The experimental campaign was performed on a HSLA Steel X60, characterized by a ferritic microstructure with fine grains and ultimate tensile strength equal to $520 \mathrm{MPa}$. The hydrogen interaction with steel was investigated by means of an advanced equipment based on an innovative high sensitivity hydrogen gas sensor. The following types of investigations were carried out [1]:

- Various permeation tests were performed with reference to EN ISO 17081:2014 increasing test temperature from $10^{\circ} \mathrm{C}$ to $60^{\circ} \mathrm{C}$.

- Afterwards a series of Hydrogen Induced Cracking nucleation tests was performed with reference to ASTM STP 692:0.

- Finally, permeation concept was applied in an innovative way to Hydrogen Induced Cracking nucleation phenomena.
\end{abstract}

\section{Introduction}

First of all, traditional permeation tests were carried out with Devanathan-Stachurski cell: the samples examined were previously coated with Pd in order to avoid the recombination of hydrogen on the output side of the reading cell and subsequent under-estimation of current by the reading system $[2,3,4]$.

Then the tests were repeated with the HELIOS instruments (patent EP2912452B1) to compare the outcomes obtained with Devanathan-Stachurski technique.

The materials used in these tests were Iron-Armco and commercial X60; also HIC tests were performed in order to estimate the critical concentration of hydrogen able to create cracks.

\section{Materials}

The composition of Iron-Armco ${ }^{\circledR}$ and X60 are shown in table 1 .
Table 1. Iron Armco and X60 composition.

\begin{tabular}{|l|c|c|}
\hline & Fe Armco & X60 \\
\hline $\mathrm{C}$ & $0,01 \%$ & $0,1343 \%$ \\
\hline $\mathrm{Mn}$ & $0,15 \%$ & $1,15 \%$ \\
\hline $\mathrm{Si}$ & - & $0,2523 \%$ \\
\hline $\mathrm{S}$ & $0,015 \%$ & $0,0047 \%$ \\
\hline $\mathrm{P}$ & $0,015 \%$ & $0,0217 \%$ \\
\hline $\mathrm{Al}$ & $0,05 \%$ & $0,0254 \%$ \\
\hline $\mathrm{Ti}$ & - & $0,022 \%$ \\
\hline $\mathrm{Nb}$ & - & $0,038 \%$ \\
\hline $\mathrm{N}$ & $0,007 \%$ & $0,0102 \%$ \\
\hline
\end{tabular}

The specimen thickness was $2 \mathrm{~mm}$ and $0,5,1$ and 2 $\mathrm{mm}$ for X60 and Iron Armco, respectively.

$\mathrm{X} 60$ steel is a HSLA whose mechanical properties are shown in table 2:

Table 2. X60 mechanical properties

\begin{tabular}{|c|c|c|}
\hline $\mathbf{R}, \mathbf{p 0 2}$ (MPa) & $\mathbf{R}_{\mathbf{m}}$ (MPa) & Elongation (\%) \\
\hline 436 & 520 & 40 \\
\hline
\end{tabular}

\footnotetext{
*Corresponding author: m.villa@letomec.com
} 
For the HIC cylindrical samples were used (13 mm diameter, $53 \mathrm{~mm}$ height).

\section{Experimental}

\subsection{Permeation Tests}

The first permeation tests were carried out with the Devanathan-Stachurski cell (STANDARD ISO 17081:2004) on the IronArmco (to make tests independent of steel type) with and without a Pd coating. Samples were previously polished with emery paper (grade 500), washed with ethanol and distilled water and then accommodated between the two semi-cells of Devanathan device: each sample was passivated using $0,1 \mathrm{~N} \mathrm{NaOH}$ solution, imposing $200 \mathrm{mV}$ potential respect to $\mathrm{Ag} / \mathrm{AgCl}$ reference; for those coated with $\mathrm{Pd}$ was used a solution of $\mathrm{PdCl}_{2}(5 \mathrm{~g} / \mathrm{L})$ and $\mathrm{NH}_{3}(28 \%$ in volume) in distilled water with an applied current density of $4 \mathrm{~mA} / \mathrm{cm}^{2}$ for $90 \mathrm{~s}$ [2].

Then the tests were repeated with the use of HELIOS II: this equipment is composed of an electrochemical cell containing the test solution where a platinum plated titanium anode is immerged. The test sample (cathode) is exposed to the solution through a hole sealed with an o-ring. Anode and cathode are connected electrically and a current is applied. On the other side of the sample a probe containing a solid-state gas sensor registers the amount of hydrogen desorbing from the dry face of the sample as represented in figure 1 (note: for HELIOS II no passivation is required):

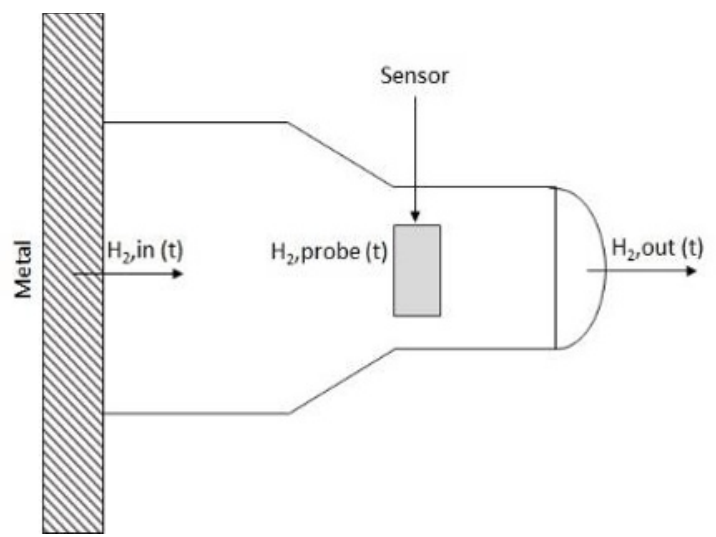

Fig. 1. HELIOS II representation

In both experiments (Devanathan and HELIOS) the solution was made of $\mathrm{NaCl} 30 \mathrm{~g} / \mathrm{L}, \mathrm{NH}_{4} \mathrm{SCN} 3 \mathrm{~g} / \mathrm{L}$, $\mathrm{CH}_{3} \mathrm{COONa} 75 \mathrm{~g} / \mathrm{L}$ and $\mathrm{CH}_{3} \mathrm{COOH} 50 \mathrm{~mL} / \mathrm{L}$ and the applied current density was $10 \mathrm{~mA} / \mathrm{cm}^{2}$.

A particular permeation test was also achieved with the aim of cracking the material and to evaluate the hydrogen flux behaviour in this condition; for this experiment a more aggressive (higher hydrogen activity) was prepared with $\mathrm{H}_{2} \mathrm{SO}_{4} 1 \mathrm{~N}$ and $\mathrm{As}_{2} \mathrm{O}_{3} 10$ $\mathrm{mg} / \mathrm{L}$ and in this case the current density was $50 \mathrm{~mA} / \mathrm{cm}^{2}$ referred to figure 4 .

\subsection{HIC}

HIC tests were performed charging cylindrical samples of material by electrochemical technique. Different combinations of solution and current densities were used, evaluating hydrogen concentration and performing microscope analysis to establish the eventual presence of cracks.

The solution used are those of table 3 while for the current density the range was $10 \div 100 \mathrm{~mA} / \mathrm{cm}^{2}$.

Samples were left the necessary time to obtain the saturation condition in the electrochemical cell; the desorption tests were carried out by means of HELIOS III: the sample was introduced in an oven working at $300^{\circ} \mathrm{C}$ temperature; the air and hydrogen flux was sucked by a pump, maintained constant by a flowmeter and passed through a solid state sensor really sensitive to hydrogen.

\section{Results}

\subsection{Permeations}

\subsubsection{Iron Armco}

The Devanathan and HELIOS permeations tests results on Fe Armco are reported in Table 3:

Table 3. Permeation results

\begin{tabular}{|c|c|c|c|}
\hline Thickness (m) & Material & $\mathrm{J}[\mathrm{mol} / \mathrm{m} \mathrm{s}]$ & $\mathrm{D}[\mathrm{m} 2 / \mathrm{s}]$ \\
\hline \multirow{3}{*}{0,0005} & Fe D & $6,96 \mathrm{E}-14$ & $1,42 \mathrm{E}-10$ \\
\hline & $\mathrm{Fe}+\mathrm{Pd} \mathrm{D}$ & $1,22 \mathrm{E}-12$ & $1,23 \mathrm{E}-10$ \\
\hline & $\mathrm{Fe} \mathrm{H}$ & $1,18 \mathrm{E}-12$ & $7,76 \mathrm{E}-11$ \\
\hline \multirow{3}{*}{0,001} & $\mathrm{Fe} \mathrm{D}$ & $3,74 \mathrm{E}-14$ & $2,45 \mathrm{E}-10$ \\
\hline & $\mathrm{Fe}+\mathrm{Pd} \mathrm{D}$ & $1,35 \mathrm{E}-12$ & $4,60 \mathrm{E}-10$ \\
\hline & $\mathrm{Fe} \mathrm{H}$ & $9,12 \mathrm{E}-13$ & $2,22 \mathrm{E}-06$ \\
\hline \multirow{3}{*}{0,002} & Fe D & $4,38 \mathrm{E}-14$ & $1,35 \mathrm{E}-09$ \\
\hline & $\mathrm{Fe}+\mathrm{Pd} \mathrm{D}$ & $1,27 \mathrm{E}-12$ & $1,38 \mathrm{E}-09$ \\
\hline & $\mathrm{Fe} \mathrm{H}$ & $1,29 \mathrm{E}-12$ & $8,87 \mathrm{E}-10$ \\
\hline
\end{tabular}




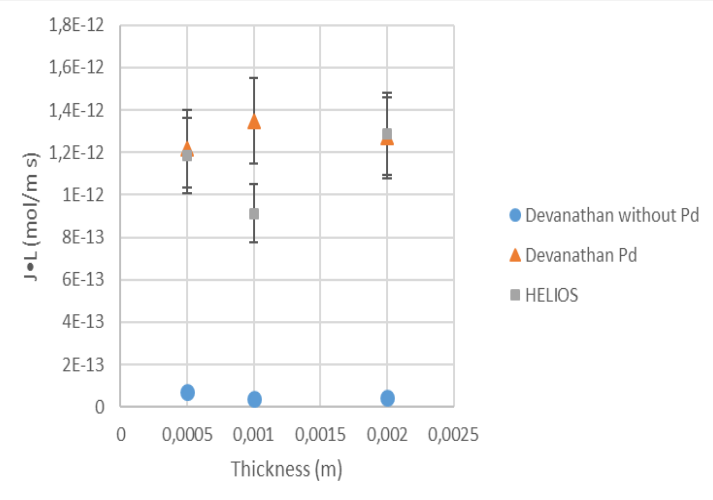

Fig. 2. Hydrogen flux for different thicknesses

From the results of table 3 it can be noticed that without the Pd coating the underestimation of hydrogen flux and concentration is not negligible. A good result is given by the evaluation of the product between current density and thickness (Pd Devanathan) and signal for thickness (HELIOS II permeation) as in figure 2.

It can be noticed that the values of figures 2 are pretty constant with reference to Devanathan Pd and HELIOS. The flux for HELIOS II is calculated through the equation 1:

$$
J_{H e}=n / A
$$

$n$ is the molar flux of hydrogen evaluated from the stationary signal and sensor calibration, while $A$ is the surface exposed to the solution; for Devanathan test the calculation is:

$$
J_{D e v}=i / F
$$

where $i$ is the current density and $F$ is the Faraday's constant.

\subsection{2 $\times 60$ steel}

Using HELIOS II, permeations at different temperatures were carried out and results are shown in figure 3:

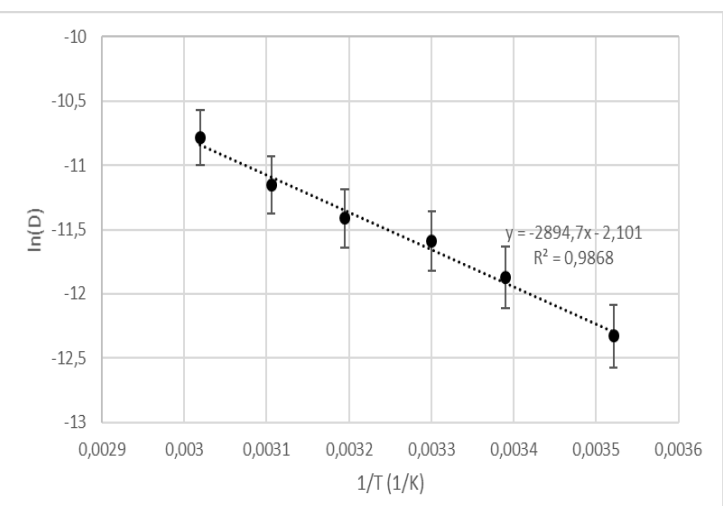

Fig. 3. Correlation between diffusion coefficient and temperature
According to the Skjellerudsveen model [5] and the Oriani traps theory [6] the binding energy of the traps were calculated:

$$
E_{b}=m \cdot R-E_{l}=18 \mathrm{~kJ} / \mathrm{mol}
$$

Where $m$ is the line slope, $R$ gas constant and $E_{l}$ is the lattice energy of pure Fe.

A permeation was achieved in crack conditions for the material: $50 \mathrm{~mA} / \mathrm{cm}^{2}$ in $\mathrm{H}_{2} \mathrm{SO}_{4} 1 \mathrm{~N}$ and $\mathrm{As}_{2} \mathrm{O}_{3} 10 \mathrm{mg} / \mathrm{L}$. The permeation curve is represented in figure 4 where the typical trend of hydrogen flux in presence of crack can be noticed.

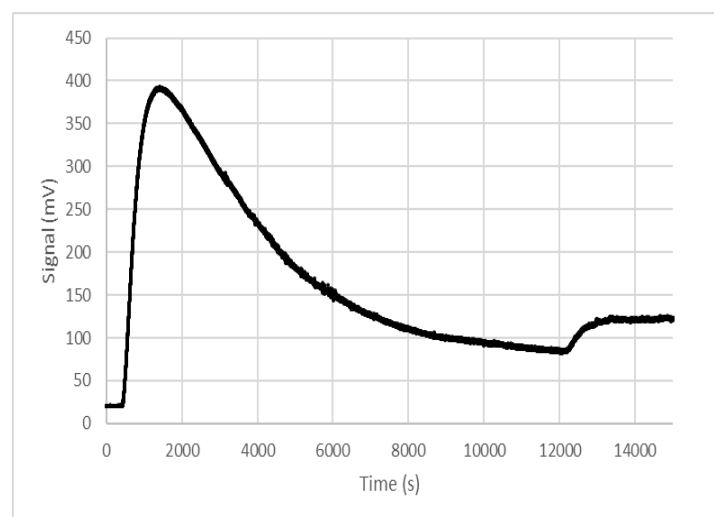

Fig. 4. X60 permeation in crack condition achieved with HELIOS II

The critical concentration corresponding to the maximum of the graph was evaluated with the following equation:

$$
C_{H}=(J L) / D
$$

Where $J$ is the hydrogen flux (derived by the sensor calibration), $L$ is the sample thickness $2 \mathrm{~mm}$ and $D$ the diffusion coefficient of hydrogen in X60 calculated by the test and equal to $8,66 \mathrm{E}-06 \mathrm{~cm}^{2} / \mathrm{s}: C_{H}$ was found to being 5,2 ppm.

\subsection{HIC}

HIC tests were carried out with use of different conditions in terms of combination between solution of table 4 and current densities. 


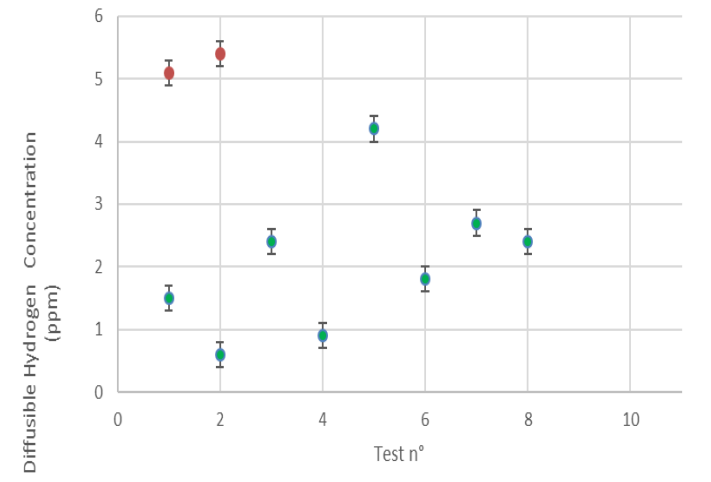

Fig. 5. Crack samples (red) and safe samples (green)

Note that the condition of sample 3 is that used for the permeation of figure 4 and the concentration of hydrogen in sample 3 is $5,1 \mathrm{ppm}$, in agreement with the value obtained by permeation test of figure 4 .

A metallographic analysis was performed and in figure 6 is represented a crack in sample of 5,1 ppm.

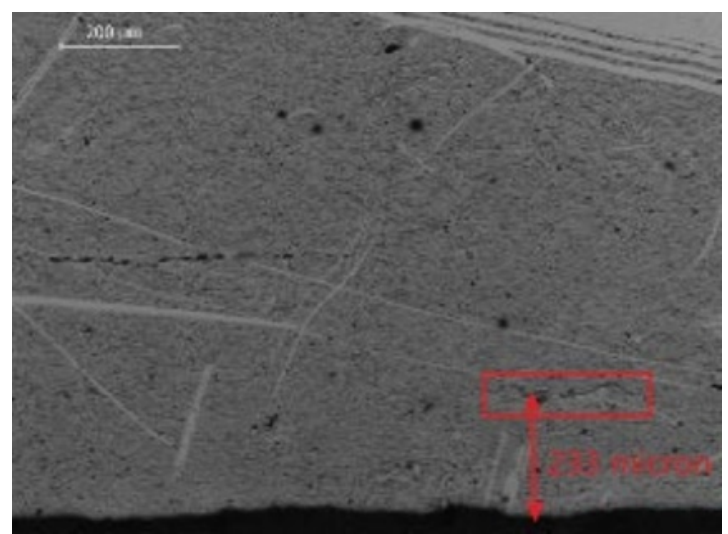

Fig. 6. Crack and distance from the sample surface

\section{References}

1. M.Villa, Controllo dei fenomeni di HE nei tubi in acciaio per Oil \& Gas: applicazione di sistemi innovativi di monitoraggio, (2018)

2. P.Manolatos, M.Jerome, Electrochim. Acta, 41, 359-365 (1996)

3. M.A.V. Devanathan, Z. Stachurski, Proc. Roy. Soc. A270, 90 (1962)

4. J. L. Crolet, Mat\&Tech, 104, 205 (2016)

5. M. Skjellerudsveen, O.M. Akselsen, V. Olden, R. Johnsen, A. Smirnova, Sintef, (2010)

6. R.A. Oriani, Acta Metall., 18, 147-157, (1970)

7. A. Turnbull, Hydrogen transport and cracking in metals. Proceedings of a conference held at the national physical laboratory, (1994)

\section{Conclusion}

Devanathan-Stachurski method can be used for the diffusion coefficient calculation but the real estimation of hydrogen flux should be done only with a previous Pd coating of the sample, at least for high values of hydrogen flux. A practical approach could be using new solid state sensor hydrogen (HELIOS). It's also well known that the Devanathan-Stachurski cell is a laboratory device which could not be applied in a real pipe: in this case HELIOS represents a good solution for monitoring hydrogen in real time: its probe can be applied directly on the wall of the pipeline and a continuous measurement is recorded. However the realization of permeation tests with Pd coating can be successfully used for calibration and validation of HELIOS instrument. 